\title{
Lack of Benefit of Heliox During Mechanical Ventilation of Subjects With Severe Air-Flow Obstruction
}

\author{
James W Leatherman MD, Ramiro Saavedra Romero MD, and Robert S Shapiro MD
}

BACKGROUND: The value of heliox (helium-oxygen mixture) for patients with severe air-flow obstruction is uncertain. The purpose of this study was to determine whether heliox could reduce the degree of hyperinflation and hypercapnia in mechanically ventilated patients with severe airflow obstruction. METHODS: This was a single-center, prospective observational study conducted in a medical ICU of an academic medical center. We assessed the impact of heliox (65-70\% helium, 30-35\% oxygen) on airway pressures and arterial blood gases of 13 subjects undergoing mechanical ventilation for severe asthma $(n=8)$ or exacerbation of COPD $(n=5)$. RESULTS: As compared with ventilation with air- $\mathrm{O}_{2}$, heliox resulted in a reduction in peak airway pressure $\left(54.1 \pm 12.6 \mathrm{~cm} \mathrm{H} \mathrm{H}_{2} \mathrm{O}\right.$ vs $\left.47.9 \pm 10.8 \mathrm{~cm} \mathrm{H} \mathrm{H}_{2} \mathrm{O}, P<.001\right)$ and $\mathrm{P}_{\mathrm{aCO}_{2}}(64.3 \pm 14.9 \mathrm{~mm} \mathrm{Hg}$ vs $62.3+15.1 \mathrm{~mm} \mathrm{Hg}, P=.01)$. In contrast, there was no change in plateau pressure $\left(25.3 \pm 5.5 \mathrm{~cm} \mathrm{H}_{2} \mathrm{O}\right.$ vs $\left.25.8 \pm 5.6 \mathrm{~cm} \mathrm{H} \mathrm{H}_{2} \mathrm{O}, P=.14\right)$ or total PEEP $\left(13.4 \pm 3.8 \mathrm{~cm} \mathrm{H}_{2} \mathrm{O}\right.$ vs $\left.13.3 \pm 4.1 \mathrm{~cm} \mathrm{H}_{2} \mathrm{O}, P=.79\right)$ in response to heliox. CONCLUSIONS: In mechanically ventilated subjects with severe air-flow obstruction, administration of heliox had no effect on indices of dynamic hyperinflation (plateau pressure and total PEEP) and resulted in only a small reduction in $\mathbf{P}_{\mathbf{a C O}_{2}}$. Key words: mechanical ventilation; heliox; obstructive lung disease; asthma; COPD. [Respir Care 2018;63(4):375-379. (C) 2018 Daedalus Enterprises]

\section{Introduction}

Heliox is a mixture of helium and oxygen whose density is much lower than that of air. ${ }^{1}$ Although heliox has been used in the setting of severe air-flow obstruction for more than 80 years, ${ }^{2}$ its role in the management of patients with asthma and COPD remains controversial..$^{3-6}$ Most previous studies have examined the use of heliox in non-intubated subjects who were breathing spontaneously or with the support of noninvasive ventilation..$^{7-11}$ A review of studies involving subjects with acute asthma concluded that breathing heliox appeared to improve pulmonary function but

The authors are affiliated with the Division of Pulmonary and Critical Care Medicine, Department of Medicine, Hennepin County Medical Center, Minneapolis, Minnesota.

The authors have disclosed no conflicts of interest.

Correspondence: James W Leatherman MD, Division of Pulmonary and Critical Care Medicine, Department of Medicine, Hennepin County Medical Center, Minneapolis, MN 55415. E-mail: James.Leatherman@hcmed.org.

DOI: $10.4187 /$ respcare. 05893 had no effect on the rate of hospital admission. ${ }^{7}$ Instead of simply breathing heliox, the latter can also be used to deliver bronchodilators by nebulization. ${ }^{8,9}$ Heliox-driven nebulization of albuterol has been shown to enhance its bronchodilator effect, ${ }^{8}$ and may reduce the rate of hospitalization of asthma patients treated in the emergency department. ${ }^{9}$ The use of heliox in subjects with exacerbations of COPD who required noninvasive ventilation has been evaluated in 2 large, multi-center randomized trials. ${ }^{10,11}$ The first study found that heliox had no significant effect on arterial blood gases or the need for intubation. ${ }^{10}$ In the second study, subjects who received heliox had a more rapid improvement in respiratory acidosis and encephalopathy, but their rates of intubation and mortality were no different from the rates of those who were treated with standard noninvasive ventilation. ${ }^{11}$

Relatively few studies have examined the use of heliox during mechanical ventilation of subjects with severe airflow obstruction. ${ }^{12-16}$ One study reported a reduction in peak airway pressure and $\mathrm{P}_{\mathrm{aCO}}$ when heliox was given to ventilated subjects with asthma, but adjustment of ventilator settings during administration of heliox limits interpretation of the data. ${ }^{12}$ Heliox has been reported to de- 
crease auto-PEEP during controlled mechanical ventilation, with average reductions ranging from 1.4 to $8 \mathrm{~cm} \mathrm{H}_{2} \mathrm{O}$.,13-16 In the current study, we evaluated the impact of heliox on lung mechanics and gas exchange of subjects who required mechanical ventilation for severe air-flow obstruction, with particular attention to its effect on indices of dynamic hyperinflation.

\section{See the Related Editorial on Page 488}

\section{Methods}

We enrolled 13 subjects with severe air-flow obstruction who had an auto-PEEP of $\geq 8 \mathrm{~cm} \mathrm{H}_{2} \mathrm{O}$, measured in the absence of applied PEEP. All subjects were studied while undergoing controlled mechanical ventilation with an Avea ventilator (CareFusion, Yorba Linda, California) that has a dedicated port for administration of heliox and an internal calibration system that guarantees equivalency of tidal volume and inspiratory flow when switching from air- $\mathrm{O}_{2}$ to heliox. Ventilator settings included tidal volume of $6-8 \mathrm{~mL} / \mathrm{kg}$ ideal body weight, breathing frequency of 10-16 breaths/min, inspiratory flow of $60 \mathrm{~L} / \mathrm{min}$ with a square inspiratory waveform, and a PEEP of $5 \mathrm{~cm} \mathrm{H}_{2} \mathrm{O}$. In all cases, the end-expiratory occlusion pressure measured with a PEEP of $5 \mathrm{~cm} \mathrm{H}_{2} \mathrm{O}$ was identical to that measured in the absence of PEEP. To maximize the potential benefit of heliox, the $\mathrm{F}_{\mathrm{IO}_{2}}$ was decreased to 0.30 (8 cases) or 0.35 ( 5 cases), using the lowest of the 2 values that provided an $\mathrm{O}_{2}$ saturation $>88 \%$. To ensure the absence of any respiratory effort, subjects were deeply sedated with propofol and fentanyl, with the addition of neuromuscular blocking agents if required.

While being ventilated with a standard gas mixture of air- $\mathrm{O}_{2}$, baseline values for peak pressure, plateau pressure $\left(\mathrm{P}_{\text {plat }}\right)$, and total PEEP were measured, and an arterial blood gas was obtained to assess $\mathrm{pH}$ and $\mathrm{P}_{\mathrm{aCO}_{2}}$. The end-expiratory occlusions used to measure total PEEP and the endinspiratory occlusions to measure $\mathrm{P}_{\text {plat }}$ were maintained for several seconds to ensure a stable pressure. Without a change in ventilator settings, the above measurements were then repeated after 30 min of ventilation with a mixture of helium and oxygen. Immediately afterward, ventilation with air- $\mathrm{O}_{2}$ was resumed, and 15-30 min later, airway pressures (but not arterial blood gases) were again measured. Airway pressures were measured in triplicate, and the average of the 3 values was used for data analysis. To minimize the likelihood that an intrinsic or drug-induced change in underlying air-flow obstruction could have confounded the results, the study was completed within $1 \mathrm{~h}$, during which time bronchodilators were withheld. The study was approved by our institution's human subjects in research review board, and informed consent was obtained

\section{QUICK LOOK}

\section{Current knowledge}

The value of heliox in the management of patients with acute exacerbations of asthma or COPD remains controversial. Most studies of heliox have focused on subjects who were breathing spontaneously or during noninvasive ventilation. There are limited data on the use of heliox during controlled mechanical ventilation.

\section{What this paper contributes to our knowledge}

We found that heliox had no effect on the degree of dynamic hyperinflation of mechanically ventilated subjects with severe air-flow obstruction. Our data suggest that heliox is unlikely to offer a clinically meaningful benefit for patients with asthma or COPD who require mechanical ventilation.

from subject surrogates. Data are expressed as mean $\pm \mathrm{SD}$. The Student $t$ test was used for statistical comparison of airway pressures and arterial blood gases. Airway pressures on air- $\mathrm{O}_{2}$ at baseline and after heliox were not different, so the baseline airway pressures were used for comparison of air- $\mathrm{O}_{2}$ with heliox.

\section{Results}

The 13 subjects included 7 women and 6 men with a median (range) age of $50(18-73) \mathrm{y}$ and a weight of $90.8 \pm 20.4 \mathrm{~kg}$. Eight subjects were being ventilated for exacerbations of asthma, whereas the remaining 5 had exacerbations of COPD. Ventilator settings included a tidal volume of $496+133 \mathrm{~mL}$, breathing frequency of $12.5 \pm 3.8$ breaths/min, and $\mathrm{F}_{\mathrm{IO}_{2}}$ of $0.32 \pm 0.08$.

Airway pressures and arterial blood gases measured during ventilation with air- $\mathrm{O}_{2}$ and heliox are shown in Table 1. As compared with air- $\mathrm{O}_{2}$, heliox produced a significant decrease in peak pressure $\left(54.1 \pm 12.6 \mathrm{~cm} \mathrm{H}_{2} \mathrm{O}\right.$ vs $\left.47.9 \pm 10.8 \mathrm{~cm} \mathrm{H}_{2} \mathrm{O}, P<.001\right)$. For individual subjects, the decrease in peak pressure in response to heliox ranged from 3 to $12 \mathrm{~cm} \mathrm{H}_{2} \mathrm{O}$ (Fig. 1). In contrast, there was no difference in $\mathrm{P}_{\text {plat }}$ during ventilation with air- $\mathrm{O}_{2}$ and heliox (25.3 $\pm 5.5 \mathrm{~cm} \mathrm{H}_{2} \mathrm{O}$ vs $25.8 \pm 5.6 \mathrm{~cm} \mathrm{H}_{2} \mathrm{O}, P=.14$ ). Similarly, total PEEP did not change in response to heliox $\left(13.4 \pm 3.8 \mathrm{~cm} \mathrm{H}_{2} \mathrm{O}\right.$ vs $\left.13.3 \pm 4.1 \mathrm{~cm} \mathrm{H}_{2} \mathrm{O}, P=.79\right)$. For individual subjects, the largest decrement in $\mathrm{P}_{\text {plat }}$ and total PEEP in response to heliox was $1 \mathrm{~cm} \mathrm{H}_{2} \mathrm{O}$ (Fig. 1). As compared with air- $\mathrm{O}_{2}$, ventilation with heliox was associated with a slight but statistically significant decrease in $\mathrm{P}_{\mathrm{aCO}_{2}}(64.3 \pm 14.8 \mathrm{~mm} \mathrm{Hg}$ vs $62.3+15.1 \mathrm{~mm} \mathrm{Hg}, P=.01)$ and increase in $\mathrm{pH}(7.24 \pm 0.09$ vs $7.27 \pm 0.09, P=.034)$. 
Table 1. Airway Pressures and Arterial Blood Gases During Ventilation With Air- $\mathrm{O}_{2}$ and Heliox

\begin{tabular}{lll}
\hline \multicolumn{1}{c}{ Variable } & \multicolumn{1}{c}{ Air- $\mathrm{O}_{2}$} & \multicolumn{1}{c}{ Heliox } \\
\hline $\mathrm{P}_{\text {peak }}, \mathrm{cm} \mathrm{H}_{2} \mathrm{O}$ & $54.1 \pm 12.6$ & $47.9 \pm 10.8^{*}$ \\
$\mathrm{P}_{\text {plat }}, \mathrm{cm} \mathrm{H}_{2} \mathrm{O}$ & $25.3 \pm 5.5$ & $25.8 \pm 5.6$ \\
Total $\mathrm{PEEP}, \mathrm{cm} \mathrm{H}_{2} \mathrm{O}$ & $13.4 \pm 3.8$ & $13.3 \pm 4.1$ \\
$\mathrm{pH}$ & $7.24 \pm 0.09$ & $7.27 \pm 0.09$ \\
$\mathrm{P}_{\mathrm{aCO}}, \mathrm{mm} \mathrm{Hg}$ & $64.3 \pm 14.8$ & $62.3 \pm 15.1^{*}$ \\
$\mathrm{P}_{\mathrm{aO}}, \mathrm{mm} \mathrm{Hg}_{2}$ & $74.8 \pm 15.2$ & $75.0 \pm 13.1$ \\
Results are mean \pm SD. $^{*}$ & & \\
$\mathrm{P}_{\text {peak }}=$ peak airway pressure & & \\
$\mathrm{P}_{\text {plat }}=$ plateau airway pressure & & \\
\hline
\end{tabular}

$\mathrm{P}_{\mathrm{aO}_{2}}$ was similar with air- $\mathrm{O}_{2}$ and heliox $(74.8 \pm 15.2 \mathrm{~mm} \mathrm{Hg}$ vs $75.0 \pm 13.1 \mathrm{~mm} \mathrm{Hg}, P=.94)$.

\section{Discussion}

The resistance to gas flow through an airway is determined by several factors, including airway caliber and configuration, flow, physical properties of the gas, such as density and viscosity, and whether gas flow is laminar or turbulent. ${ }^{1,3}$ The resistive pressure drop across the airway is much lower when gas flow is laminar instead of turbulent. The density of a gas has no effect on the resistance to laminar flow, but under turbulent conditions, flow is improved with lower gas density. ${ }^{3}$

Heliox is a biologically inert gas whose most important physical property is that it has a much lower density than air. As such, heliox will decrease frictional resistance when gas flow is turbulent but will have no effect on resistance to laminar flow. ${ }^{3}$ In addition to the above consideration, the lower density of heliox also decreases the Reynolds number, a dimensionless quantity that governs whether gas flow is likely to be laminar or turbulent ${ }^{1,3}$ : Reynolds number $=(\mathrm{pvD}) / \mathrm{n}$, where $\mathrm{p}$ represents gas density, $\mathrm{v}$ is velocity, $\mathrm{D}$ is airway diameter, and $\mathrm{n}$ is viscosity.

Because the Reynolds number is positively related to velocity and airway caliber, higher gas velocity and larger airway diameter favor turbulent flow, whereas laminar flow will be present when gas is flowing at slower velocity through small airways. Ventilation with heliox will be associated with a much lower Reynolds number than ventilation with air- $\mathrm{O}_{2}$ because of its much lower gas density. Therefore, there are 2 principle mechanisms by which heliox could theoretically be of benefit: (1) decreasing airway resistance in regions with turbulent flow and (2) lowering the Reynolds number, thereby promoting laminar rather than turbulent flow.

The key finding in the current study was that administration of 70:30 heliox had no effect on either $\mathrm{P}_{\text {plat }}$ or total
PEEP in mechanically ventilated subjects with severe airflow obstruction. In contrast, heliox resulted in a significant decrease in peak pressure that was due entirely to a reduction in inspiratory flow-resistive pressure (peak pressure minus $\mathrm{P}_{\text {plat }}$ ). There was a small reduction in $\mathrm{P}_{\mathrm{aCO}}$ with heliox.

We believe that the findings of our study can be readily explained by the physical properties of heliox mentioned above. During inspiration, tidal volume is delivered at high velocity through the endotracheal tube and larger airways, conditions that would favor turbulent flow. Because the resistance to turbulent gas flow is highly dependent on gas density, this would account for the observed reduction in inspiratory flow-resistive pressure (peak pressure minus $\mathrm{P}_{\text {plat }}$ ) with heliox. In contrast, during expiration, the resistance to gas flow is predominantly located in the small peripheral airways, and gas velocities are much lower due to the large total cross-sectional area of numerous parallel pathways, factors that would encourage laminar flow. ${ }^{3} \mathrm{Be}-$ cause laminar flow is independent of gas density, heliox would not be expected to enhance expiratory flow or lessen indices of hyperinflation (auto-PEEP, $\mathrm{P}_{\text {plat }}$ ), as was observed in the current study. In support of this concept, a previous study that found no effect of heliox on dynamic hyperinflation in subjects with COPD was interpreted as evidence that the flow-limiting segment was in the peripheral airways, where the viscous (and density-independent) mechanism is operative. ${ }^{17}$ In brief, the Reynolds number during expiration may be low enough during ventilation with air- $\mathrm{O}_{2}$ that laminar flow is already established, rendering its further reduction by heliox irrelevant.

In contrast to the findings of our study, some studies have reported a reduction in the degree of hyperinflation in response to heliox. ${ }^{13-16}$ Tassaux et $\mathrm{al}^{13}$ found that heliox reduced auto-PEEP in 22 of 23 subjects with COPD, with an average reduction of $4 \mathrm{~cm} \mathrm{H}_{2} \mathrm{O}$. Surprisingly, inspiratory flow-resistive pressure remained unchanged. Concern about the validity of the data reported in this study was raised in an accompanying editorial because the baseline peak pressure was only $30 \mathrm{~cm} \mathrm{H}_{2} \mathrm{O}$ and calculated airway resistance was normal. ${ }^{18}$ In a subsequent study of 25 subjects with COPD, Lee et al ${ }^{16}$ reported an even more dramatic impact of heliox on dynamic hyperinflation, with the average auto-PEEP falling from 13 to $5 \mathrm{~cm} \mathrm{H}_{2} \mathrm{O}$. As with the earlier study by Tassaux et $\mathrm{al}_{1}{ }^{13}$ there was minimal change in inspiratory flow-resistive pressure (average, $-2 \mathrm{~cm} \mathrm{H}_{2} \mathrm{O}$ ) in response to heliox. Therefore, the findings in our study and these 2 previous studies differ in 2 key respects. First, our subjects had markedly increased inspiratory flow-resistive pressure and airway resistance at baseline, and both were significantly decreased by heliox, whereas in the 2 prior studies, heliox had negligible effect on inspiratory flow-resistive pressure. Second, we observed no effect of heliox on indices of hyperinflation $\left(\mathrm{P}_{\text {plat }}\right.$ and 

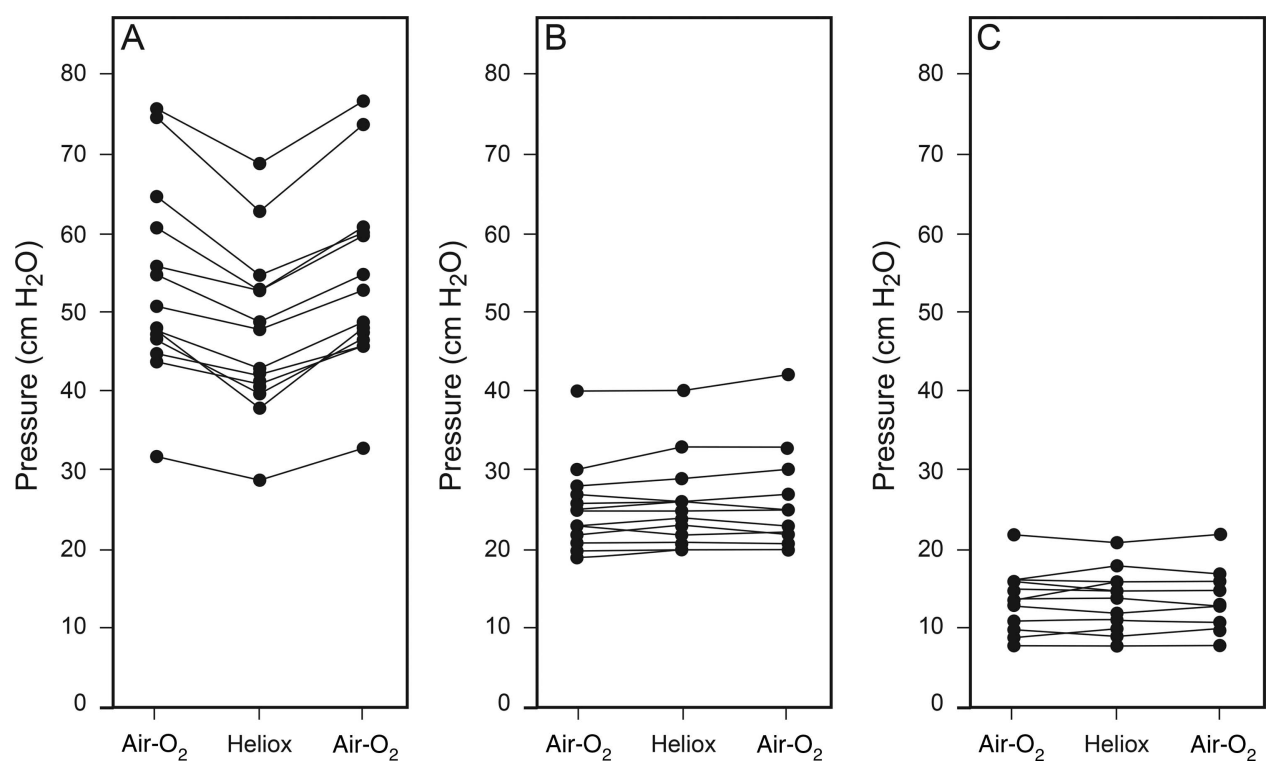

Fig. 1. Peak airway pressure $(A)$, plateau airway pressure $(B)$, and total PEEP $(C)$ for individual subjects $(N=13)$ during ventilation with air- $\mathrm{O}_{2}$ and heliox.

auto-PEEP), whereas the latter was significantly reduced by heliox in the 2 earlier studies.

The reasons for the discrepancy between the findings of our study and those of earlier reports are unclear. The 3 studies were very similar in many respects, including the use of 70:30 concentrations of heliox and similar tidal volume and breathing frequency. The type of subjects studied differed somewhat in that the earlier studies focused solely on mechanically ventilated individuals with COPD, whereas 8 of our 13 subjects were undergoing mechanical ventilation for exacerbations of asthma. However, the response to heliox in our 8 subjects with asthma did not differ from that seen in the 5 subjects who had COPD. Another difference is that our subjects were all studied while receiving $5 \mathrm{~cm} \mathrm{H}_{2} \mathrm{O}$ of PEEP, whereas in the 2 earlier studies, no PEEP was used. However, the measured end-expiratory occlusion pressure in each of our subjects was identical at PEEP of zero and $5 \mathrm{~cm} \mathrm{H}_{2} \mathrm{O}$, so this would seem highly unlikely to account for a difference in heliox response. Finally, we used a different ventilator than was used in the earlier studies. It is well known that there is considerable variability among ventilators with regard to their operation during ventilation with heliox. ${ }^{19}$ The Avea ventilator (Care Fusion) that was used in our study is an FDAcleared commercial ventilator that has been specifically designed to operate with heliox without need for adjustments in settings, giving us confidence that there were no technical factors that would account for our findings. However, the ventilator (Servo, Maquet, Wayne, New Jersey) used in the earlier studies is also believed to be appropriate for use with heliox without need for manual adjustment in volume or flow. Therefore, the specific ventilator used might not readily account for the observed differences in heliox response. In brief, the reason for the discrepancy between our findings and those reported previously is not apparent.

A potential limitation of the current study is the relatively small sample size. Had we studied a larger number of subjects, it is possible that we might have identified certain individuals who would have responded favorably to heliox. On the other hand, the failure of heliox to affect indices of dynamic hyperinflation was a consistent and uniform finding in each of the 13 consecutive subjects we studied (Fig. 1). Therefore, it is reasonable to conclude that the likelihood of a positive response to heliox would be very low, even if additional subjects were studied.

Given the conflicting data regarding the benefit of heliox administration during mechanical ventilation of patients with severe air-flow obstruction, what approach should the practitioner take when considering this therapeutic option? We would recommend that if a trial of heliox is undertaken, it should be done using the highest concentration of helium possible (minimum 60\%) that allows an adequate arterial oxygen concentration. Heliox is an inert gas with no intrinsic bronchodilator or anti-inflammatory properties, and any beneficial effect should be seen rapidly. Therefore, assessment of the effect of heliox on airway pressures and arterial blood gases should be made soon (15-30 min) after its initiation, without change in ventilator settings or administration of additional bronchodilator. A more delayed improvement in airway pressures or gas exchange would be far more likely to be due to other factors and should not be attributed to heliox. In our view, an isolated reduction in peak pressure without change in $\mathrm{P}_{\text {plat }}$ or auto-PEEP would not justify its contin- 


\section{Heliox for Severe Air-Flow Obstruction}

uation. Our experience would suggest that a clinically meaningful response to heliox is unlikely.

\section{REFERENCES}

1. Hess DR, Fink JB, Venkataraman ST, Kim IK, Myers TR, Tano BD. The history and physics of heliox. Respir Care 2006;51(6):608-612.

2. Barach AL, Eckman M. The use of helium as a new therapeutic gas. Anesth Analg 1935;14(5):210-215.

3. McCarvey JM, Pollack CV. Heliox in airway management. Emerg Med Clin N Am 2008;26(4):905-920.

4. Diehl JL, Peigne V, Guérot E, Faisy C, Lecourt L, Mercat A. Helium in the adult critical care setting. Ann Intensive Care 2011;1(1):24.

5. Colebourn CL. Barber V, Young JD. Use of heliox-oxygen mixture in adult patients presenting with exacerbations of asthma and chronic obstructive pulmonary disease: a systematic review. Anaesthesia 2007;62(1):34-42.

6. Levy SD, Alladina JW, Hibbert K, Harris RS, Bajwa EK, Hess DR. High-flow oxygen and other inhaled therapies in intensive care units. Lancet 2016;387(10030):1867-1878.

7. Rodrigo G, Pollack C, Rodrigo C, Rowe BH. Heliox for nonintubated acute asthma patients. Cochrane Database Syst Rev 2006;18; (4):CD002884.

8. El-Khatib MF, Jamaleddine G, Kanj N, Zeineddine S, Chami H, Bou-Akl I, et al. Effect of heliox- and air-driven nebulized bronchodilator therapy on lung function of patients with asthma. Lung 2014; 192(3):377-383.

9. Rodrigo GJ, Castro-Rodriguez JA. Heliox-driven $\beta 2$-agonists nebulization for children and adults with acute asthma: a systematic review with meta-analysis. Ann Allergy Asthma Immunol 2014;112(1): 29-34.

10. Maggiore SM, Richard JC, Abroug F, Diehl JL, Antonelli M, Sauder $\mathrm{P}$, et al. A multicenter, randomized trial of noninvasive ventilation with helium-oxygen mixture in exacerbations of chronic obstructive lung disease. Crit Care Med 2010;38(1):145-151.
11. Jolliet P, Ouanes-Besbes L, Abroug F, Ben Khelil J, Besbes M, Garnero A, et al. A multicenter randomized trial assessing the efficacy of helium/oxygen in severe exacerbations of chronic obstructive pulmonary disease. Am J Respir Crit Care Med 2017;195(7): 871-880.

12. Gluck EH, Onorato DJ, Castriotta R. Heliox-oxygen mixtures in intubated patients with status asthmaticus and respiratory acidosis. Chest 1990;98(3):693-698.

13. Tassaux D, Jolliet P, Roeseler J, Chevrolet JC. Effects of heliumoxygen on intrinsic positive end-expiratory pressure in intubated and mechanically ventilated patients with severe chronic obstructive pulmonary disease. Crit Care Med 2000;28(8):2721-2728.

14. Gainnier M, Arnal JM, Gerbeaux P, Donati S, Papazian L, Sainty JM. Helium-oxygen reduces work of breathing in mechanically ventilated patients with chronic obstructive pulmonary disease. Intensive Care Med 2003;29(10):1666-1670.

15. Jolliet P, Watremez C, Roeseler J, Ngengiyumva JC, de Kock M, Clerbeaux T, et al. Comparative effects of helium-oxygen and external positive end-expiratory pressure on respiratory mechanics, gas exchange, and ventilation-perfusion relationships in mechanically ventilated patients with chronic obstructive pulmonary disease. Intensive Care Med 2003;29(9):1442-1450.

16. Lee DL, Lee H, Chang HW, Chang AY, Lin SL, Huang YC. Heliox improves hemodynamics in mechanically ventilated patient with chronic obstructive pulmonary disease with systolic pressure variations. Crit Care Med 2005;33(5):968-973.

17. Pecchiari M, Pelucchi A, D’Angelo E, Foresi A, Milic-Emili J, D'Angelo E. Effect of heliox breathing on dynamic hyperinflation in COPD patients. Chest 2004;125(6):2075-2082.

18. Marini JJ. Heliox in chronic obstructive pulmonary disease ... time to lighten up? Crit Care Med 2000;28(8):3086-3088.

19. Tassaux D, Jolliet P, Thouret JM, Roeseler J, Dorne R, Chevrolet JC. Calibration of seven ICU ventilators for mechanical ventilation with helium-oxygen mixtures. Am J Respir Crit Care Med 1999;160(1):22-32.

This article is approved for Continuing Respiratory Care Education credit. For information and to obtain your CRCE

(free to AARC members) visit www.rcjournal.com

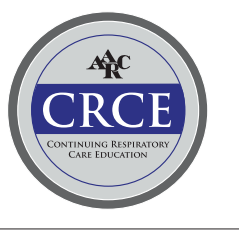

